\title{
The Effect of Low Self-esteem on Development of Depression: A Meta-analysis
}

\author{
Danlan Huang \\ Nanjing Foreign Language School, Nanjing 210008, China, amailinuse@163.com
}

\begin{abstract}
Self-esteem is defined as a person's satisfaction, confidence and perceived worth of him. Depression is a widespread and severe social problem. For people with depression, their life standards are seriously affected. There is evidence that low self-esteem and depression are related. This article looks at the effects of low self-esteem on depression, and suggests that low self-esteem may be a cause for depression. Through a meta-analysis method, data on participants' self-esteem and depression is extracted and analyzed from past researches on the correlation between self-esteem and depression. The participants range from adolescents to elderly as well as special groups. Then, a causational relationship is deduced from the correlation. The results suggest that low self-esteem can be one of the reasons of depression, showing a need for raising people's self-esteem to prevent depression. The results also indicate a need for future researches to focus on how effective different ways of elevating self-esteem are.
\end{abstract}

Keywords: self-esteem, depression, causation.

\section{BACKGROUND}

Studies have been conducted on the causes of depression and different models have been constructed to explain this mental status. The models are based on behavioral, cognitive, environmental and genetic factors that cause depression, and thus have conflicting views about how self-esteem and depression are related. Depression is defined as a long-term bad state of mood and resistance towards activity [1]. Self-esteem is defined as one's subjective attitudes about his own worth [2]. In this article, with the summarizing of past studies which obtained the results through empirical observation, it is postulated that low self-esteem increases the risk for depression.

It is clear that low self-esteem easily leads to self-accusation when undesirable events happen, which can give rise to a feeling of worthlessness and possibly depression. While opponents may argue that low self-esteem is a result of depression after the bad events, the emotions caused by the events are usually short-term, which do not qualify as a state of depression. On the other hand, low self-esteem creates continuous hate directed toward oneself, magnifying and lengthening the negative feelings whenever people with low self-esteem feel bad. Because this influence is long-lasting, it may be the reason why they get depressed [3].
Depression is defined as a long-term bad state of mood and resistance towards activity [1]. It is a very widespread symptom. According to the WHO, it is estimated that 4.4 percent of people worldwide are suffering from depression [4]. In addition, this number is rising rapidly, displaying an 18 percent increase for people who live with depression [5]. In some people, depression can worsen to clinical situations, such as major depressive disorder. It also gives rise to other problems. For example, in children, depression greatly affects their normal psychological development, and older people with depression are in higher danger of contracting serious physical diseases. Other risks because of depression include social withdrawal, substance abuse and suicidal behavior, making it a great burden for public health [6].

One of the standard measurement tools for self-esteem is Rosenberg Self-esteem Scale [2], self-esteem is defined as one's subjective attitudes about his own worth, including beliefs, emotional states and feelings. It reflects how much an individual respect himself. Behavioral, cognitive, environmental and genetic factors play a part in the development of self-esteem [3]. Often considered as an important aspect of psychological health, self-esteem exerts great influence on one's emotions, behaviors and abilities [7]. People with high self-esteem are convinced that they should work towards a better life and make progress and achieve. Furthermore, it was suggested by studies that 
high self-esteem allows one to love others, treat them with kindness, and consequently form social bonds [8].

As seen from the descriptions of depression and self-esteem, there could be a relationship between the two: a person deprived of self-esteem can easily become frustrated when he or she fails, bringing about bad feelings or sometimes depression; the negative emotions, in turn, can lead to negative beliefs about oneself, which further lowers the self-esteem, creating a vicious cycle. It is important to figure out whether depression or low self-esteem comes first in this problem, as only through this can the social problems associated with depression and low self-esteem be better controlled.

Many studies have been conducted on the correlation between low self-esteem and depression. It was suggested that these two are closely related [9]. Others considered a reciprocal relationship [10]. Different researchers had shown both aspects, which depression could potentially lead to low self-esteem [11] and that depression is possibly a consequence of a drop in self-esteem [12]. It was also indicated by many studies that self-esteem plays an important mediating role in the development of depression [13]. In conclusion, there is a close relationship between the two, but different studies gave different answers for which one the true cause is [14]. As discussed above, there is an urgent need to ease the social problem of depression. Preventing the disorder can be more desirable both economically and for the patients, but the work of primary prevention cannot be done without first identifying the true reason why people fall depressed. Based on this, a research is required to find out the root cause. This article used data from a number of past research papers and, using the meta-analysis method, sought the answer to help establish a more comprehensive understanding of depression. By combining and comparing the results of past researches, a more complete picture may be constructed to settle the problem.

\section{METHODS}

\subsection{Literature Search and Selection Criteria}

The search terms ("depression" OR "depressive" OR "anhedonia") in all fields AND ("self-esteem" OR "self-worth" OR "self-regard" OR "self-respect" OR "self-integrity") in the title were used in MDPI, since articles in this database can be accessed for free. Multiple synonyms and near-synonyms of depression and self-esteem were used to avoid missing out relevant articles.

\subsection{Eligibility Criteria}

This study included either longitudinal, cross-sectional or cohort studies that reported the correlation between self-esteem and depression. Those with self-esteem and depression as mediators were also included to make full use of accessible data. The exclusion criteria excluded any articles with the following characteristics: a sample size below 20, case studies, pure theoretical articles, articles not written in English, articles with inaccessible data.

\subsection{Data Extraction}

By reading each article, the following information is extracted: the location of the study, the type of study, participant data including the subjects tested, inclusion criteria for participants and their age, statistics including correlation coefficients and $\mathrm{p}$ values. Those data were then transferred to a Microsoft Excel 2010 worksheet, which was then analyzed with descriptive statistics and inferential statistics using the functions in Microsoft Excel 2010

\subsection{Study Outcomes}

The primary outcome of this study was to find out the association between low self-esteem and depression. Other outcomes were the differences of self-esteem and depression in different groups of people.

\subsection{Statistical Analysis}

Using the functions in Microsoft Excel 2010, the extracted data was put in order and analyzed. Functions that were used include SUMPRODUCT for the pooled average values, T.TEST for Student's t-test, SUM and AVERAGE. For clarity, charts and figures were also constructed in the worksheet then transferred to this article.

\section{RESULTS}

\subsection{Search Results}

41 articles were found using the search terms above. Then obviously unrelated ones, such as those which looked at the relationship between self-esteem and addiction were ruled out by reading their titles, leaving 15 articles. After that, the articles were skimmed through, and those which included investigation of self-esteem and depression but did not look at the correlation between them are taken out, leaving 9 eligible articles. The process of reducing is shown in figure 1 . 


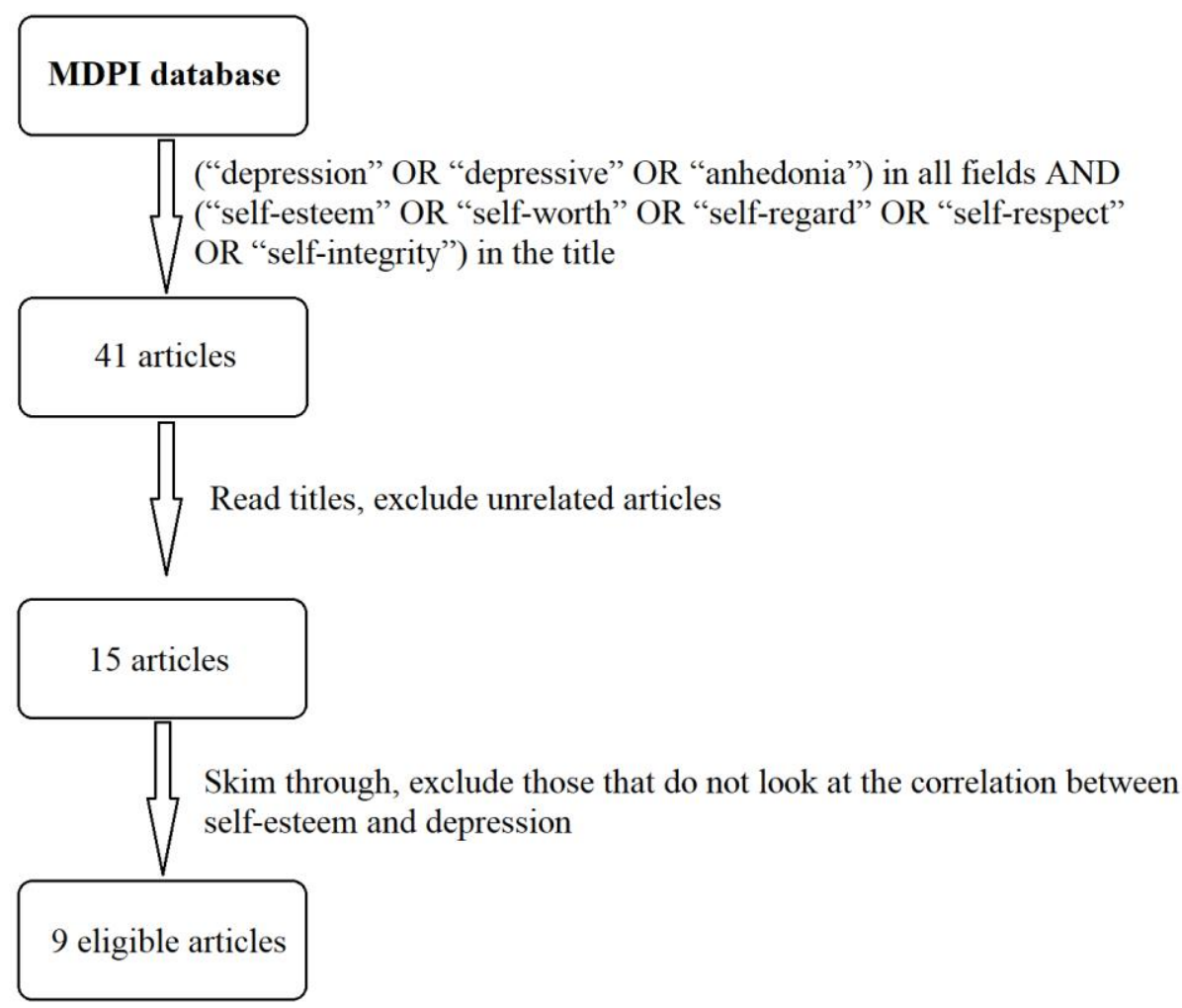

Figure 1. Flow chart for the process of choosing eligible articles

\subsection{Characteristics of the Included Studies}

Of the 9 chosen articles, 4 of them studied students and 2 studied elderly, with the remaining 3 studying adults without specifying the age. On the location of the studies, 6 came from Asia, 1 came from the US, 1 came from Chile, and 1 came from Spain. There were 6 cross-sectional studies and 3 longitudinal studies among the chosen 9.

\subsection{Self-esteem and Depression Among Participants}

8 in 9 of the studies chosen gave the mean (M) and standard deviation (SD) on self-esteem and depression scores, respectively, and 5 of them also gave the correlation coefficient between self-esteem scores and depression scores. These data were put into a Microsoft Excel 2010 worksheet for further analysis. The characteristics of the participants are shown in Table 1.

Table 1. The characteristics of the participants of the included articles [13,14,21,27-32]

\begin{tabular}{|c|c|c|c|c|c|c|c|c|c|c|c|c|}
\hline $\begin{array}{l}\text { No. } \\
\text { (Ref) }\end{array}$ & $\begin{array}{l}\text { Author, } \\
\text { Year }\end{array}$ & $\begin{array}{l}\text { Study } \\
\text { Area }\end{array}$ & $\begin{array}{l}\text { Study } \\
\text { Design }\end{array}$ & Participants & $\mathrm{n}$ & Age $M$ & Age SD & $\begin{array}{l}\text { Self-esteem } \\
\text { M }\end{array}$ & $\begin{array}{l}\text { Self-esteem } \\
\text { SD }\end{array}$ & $\begin{array}{l}\text { Depression } \\
\text { M }\end{array}$ & $\begin{array}{l}\text { Depression } \\
\text { SD }\end{array}$ & $\mathrm{r}$ value \\
\hline $\begin{array}{c}1 . \\
{[21]}\end{array}$ & R Bipeta et al., 2020 & $\begin{array}{l}\text { Helsinki, } \\
\text { India }\end{array}$ & $\begin{array}{l}\text { Cross-sectional } \\
\text { study }\end{array}$ & Psychiatrics & 152 & 31.20 & 9.00 & 13.80 & 5.90 & 35.20 & 5.90 & \\
\hline \multirow[t]{5}{*}{$\begin{array}{r}2 . \\
{[32]}\end{array}$} & $\begin{array}{l}\text { Wenceslao Peñate et al., } \\
2020\end{array}$ & $\begin{array}{l}\text { Concepción, } \\
\text { Chile }\end{array}$ & $\begin{array}{c}\text { Longlitudinal } \\
\text { study }\end{array}$ & Adolescents & 467 & & & 24.37 & 5.13 & 11.25 & 3.11 & -0.37 \\
\hline & & & & & & & & 24.94 & 4.55 & 11.72 & 2.94 & \\
\hline & & & & & & & & 24.62 & 5.05 & 11.62 & 3.22 & \\
\hline & & & & & & & & 24.91 & 5.44 & 11.57 & 3.36 & \\
\hline & & & & & & & & 24.92 & 5.24 & 11.42 & 3.19 & \\
\hline \multirow[t]{2}{*}{$\begin{array}{c}3 . \\
{[31]}\end{array}$} & $\begin{array}{l}\text { Angel Nga Man Leung et } \\
\text { al., } 2021\end{array}$ & $\begin{array}{c}\text { Hong Kong, } \\
\text { China }\end{array}$ & $\begin{array}{l}\text { Cross-sectional } \\
\text { study }\end{array}$ & $\begin{array}{c}\text { University } \\
\text { students }\end{array}$ & 347 & 20.27 & 2.02 & & & & & \\
\hline & & & & $\begin{array}{c}\text { University } \\
\text { students }\end{array}$ & 233 & 21.05 & 1.80 & & & & & \\
\hline $\begin{array}{c}4 . \\
{[13]}\end{array}$ & Yali Deng et al., 2020 & China & $\begin{array}{l}\text { Cross-sectional } \\
\text { study }\end{array}$ & Drug users & 1895 & & & 26.70 & 4.00 & 48.40 & 8.30 & -0.391 \\
\hline $\begin{array}{c}5 . \\
{[14]}\end{array}$ & Hyun Jin Lee et al., 2019 & Korea & $\begin{array}{l}\text { Cross-sectional } \\
\text { study }\end{array}$ & Elderly & 701 & & & 4.83 & 1.24 & 17.42 & 6.45 & \\
\hline $\begin{array}{c}6 . \\
{[27]}\end{array}$ & $\begin{array}{l}\text { María Angeles Peláez- } \\
\text { Fernández et al., } 2021\end{array}$ & Spain & $\begin{array}{l}\text { Cross-sectional } \\
\text { study }\end{array}$ & Unemployed & 530 & 34.60 & & 3.40 & 1.16 & 0.86 & 0.80 & -0.36 \\
\hline $\begin{array}{c}7 . \\
{[28]}\end{array}$ & Shervin Assari et al., 2018 & America & $\begin{array}{c}\begin{array}{c}\text { Longlitudinal } \\
\text { study }\end{array} \\
\end{array}$ & Elderly & 1439 & 75.14 & 6.67 & 10.50 & 1.54 & 1.56 & 0.62 & -0.55 \\
\hline $\begin{array}{c}8 . \\
{[30]}\end{array}$ & $\begin{array}{c}\text { Sumaira Kayani et al., } \\
2018 \\
\end{array}$ & Pakistan & $\begin{array}{l}\text { Cross-sectional } \\
\text { study }\end{array}$ & Students & 358 & 20.30 & 1.15 & 2.78 & 0.52 & 2.06 & 0.53 & -0.146 \\
\hline \multirow[t]{8}{*}{$\begin{array}{c}9 . \\
{[29]}\end{array}$} & $\begin{array}{c}\text { Jeong-Won Han et al., } \\
2020 \\
\end{array}$ & Korea & $\begin{array}{c}\text { Longlitudinal } \\
\text { study }\end{array}$ & $\begin{array}{c}\text { Postnatal } \\
\text { women }\end{array}$ & 423 & 30.59 & 3.60 & 3.77 & 0.47 & 1.78 & 0.66 & \\
\hline & & & & & & & & 3.74 & 0.48 & 1.75 & 0.63 & \\
\hline & & & & & & & & 3.71 & 0.45 & 1.82 & 0.58 & \\
\hline & & & & & & & & 3.71 & 0.55 & 1.86 & 0.66 & \\
\hline & & & & & & & & 3.77 & 0.52 & 1.88 & 0.64 & \\
\hline & & & & & & & & 3.81 & 0.52 & 1.86 & 0.64 & \\
\hline & & & & & & & & 3.83 & 0.53 & 1.82 & 0.66 & \\
\hline & & & & & & & & 3.86 & 0.52 & 1.72 & 0.63 & \\
\hline
\end{tabular}




\subsection{The Correlation Between Low Self-Esteem and Depression}

All the studies that gave the correlation coefficient of self-esteem and depression scores are statistically significant $(p<0.01)$, so a weighted average was calculated for the given values. The result showed that low self-esteem is strongly linked to depression $(\mathrm{r}=-0.30$, $\mathrm{p}<0.01)$. For the 8 studies that included the mean and standard deviation values, after excluding abnormal negative values, the rest of them were used in a t-test on the self-esteem scores and depression scores. The result showed a medium-sized effect of self-esteem on depression $(\mathrm{d}=0.69, \mathrm{r}=0.25)$. After that, Fisher's $\mathrm{F}$ was applied to observe the difference between the two sets of data. The result showed a significant effect $(\mathrm{F}=8.73>$ $\mathrm{F}(4015,4015))$.

\section{DISCUSSION}

\subsection{General Discussion}

A meta-analysis on 9 papers found that low self-esteem is correlated with depressive symptoms. This is consistent with previous research [15]. One of them stated that higher self-esteem was associated with lower depression in students [16]. Some others noted that low self-esteem in new mothers has a negative correlation with depression [17], that low self-esteem in parents may cause depression [18], and that post-partum depression is predicted by low self-esteem [19]. Here, it is further postulated that low self-esteem could be one of the causes of depression. Although correlation does not mean causation, low self-esteem would make people think they do not deserve positive emotions, as research has shown that self-esteem possibly make people feel that they deserve happiness [8]. This would make people with low self-esteem stay in a negative state of mind for a long time even without any proximate cause, eventually aggravating to depression. Furthermore, it has been suggested that enhanced self-esteem attenuates behavioral and emotional problems [20], which means low self-esteem would mean a higher risk for these problems.

Low self-esteem, in turn, has many possible causes. Studies indicated that perceived stigma cause low self-esteem in people experiencing mental illnesses and substance abuse [21]. Low perceived social support was also found to associate with low self-esteem [13]. It was also suggested that consistent failures lower self-esteem significantly [7]. However, it is unlikely that depression is the primary cause of low self-esteem, because for a healthy person, depression does not initiate on its own and there should be a cause [22]. Last but not least, it is also unlikely that depression and low self-esteem are derived from the same cause. Although bad events in life, such as being abused, experiencing a series of failures, being socially isolated and losing a job does simultaneously lead to bad mood and a decrease in self-esteem, the bad mood does not tend to last long after the event because healthy people's ability to adapt to changes in life is rather strong [23]. On the contrary, the low self-esteem caused by the event can be long-lasting [24], possibly leading to depression based on the theory described above. In conclusion, low self-esteem may cause depression in psychologically healthy individuals.

\subsection{Heterogeneity Among Studies}

The studies included used participants differing widely by age, life conditions, ration, etc., and self-esteem and depression scores also fluctuated over time as shown in the longitudinal studies. As a result, there is indeed heterogeneity among the articles included. This may be the result of different methods and study designs used in the included studies. For instance, different questionnaires were used when measuring depression and self-esteem, possibly generating variance.

\subsection{Suggestions}

Based on the findings above, a possible answer to why the number of people suffering from depression is rapidly increasing has been found. Thus, in order to reduce the prevalence of depression across the globe, methods to improve people's self-esteem should be applied. According to past research, a moderate increase of self-esteem during adolescence is identified [25], which varies among individuals under different parenting styles [26], making it important for parents to receive advice on parenting styles to avoid harming self-esteem and increasing their risk of contracting depression. Also, it is shown that unemployed people have significantly lower self-esteem and higher depression than ordinary people [27]. This shows the need for the government to focus efforts on job losses, since it possibly gives rise to low self-esteem and psychological issues. Moreover, in elderly people living in multi-generation households, self-esteem of individuals may suffer from regular conflict [14]. The community should find out ways to bring the family members together, such as holding family activities, in order to protect their self-esteem.

\subsection{Implications for Future Research}

In addition to establishing protection measures, it is also suggested by the results that future studies should focus on the efficacy of different measures to improve self-esteem. For example, studies can compare between the effects of unconditional positive regard and socialization on self-esteem to identify the better 
method to help people with low self-esteem combat their negative thought patterns. It is also important to examine what causes low self-esteem for a complete prevention of depression.

\subsection{Limitations}

This article has several limitations. Firstly, the articles were predominantly conducted in Asia, hindering generalizability. Secondly, only 9 articles were found in the final dataset due to paywalls, possibly causing larger sampling error. Thirdly, the ages of participants were not uniformly distributed.

\section{CONCLUSION}

A meta-analysis studied how low self-esteem influences depressive symptoms. The results found a strong correlation between low self-esteem and depression, and a postulation that low self-esteem could be a cause for depression was put forward and reasoned. Although significant heterogeneity existed among the included studies, the data analysis enabled the detection of a regular pattern between two psychological variables, namely low self-esteem as a possible cause of depression. The results indicated a need for further research on methods to better raise people's self-esteem and cope with depression. Since everyone in the society deserves to live a pleasant life free from long-term depression, there is a crucial need for people to understand their perceptions of self and self-esteem and long-term mental wellbeing to make the world a better place.

\section{REFERENCES}

[1] De Zwart P., Jeronimus B., \& De Jonge, P. (2019). Empirical evidence for definitions of episode, remission, recovery, relapse and recurrence in depression: a systematic review. Epidemiology and Psychiatric Sciences. 28(5), 544-562. https://doi.org/10.1017/S2045796018000227.

[2] Rosenberg, M. (1965). Society and the Adolescent Self-Image. Princeton University Press: Princeton, NJ, USA.

[3] Hewitt, J. P. (2009). Oxford Handbook of Positive Psychology. Oxford University Press. pp. 217-224. ISBN 978-0-19-518724-3.

[4] Solomon, A. (2006). Opinion | Our Great Depression. The New York Times. ISSN 0362-4331. Retrieved 27 June 2019.

[5] France-Presse, A. (2017). Depression is leading cause of disability worldwide, says WHO study. The Guardian. ISSN 0261-3077. Retrieved 27 June 2019.
[6] Reynolds C.F., \& Patel V. (2017). Screening for depression: the global mental health context. World Psychiatry. 16(3). pp316-317. https://doi.org/10.1002/wps.20459.

[7] Crocker, J., Sommers, S. R., \& Luhtanen, R. K. (2002). Hopes Dashed and Dreams Fulfilled: Contingencies of Self-Worth and Graduate School Admissions. Personality and Social Psychology Bulletin. 28(9): 1275-1286. doi:10.1177/01461672022812012.

[8] Nathaniel, B. (1987). Cómo mejorar su autoestima. Ediciones Paidós Ibérica. ISBN 978-84-493-2347-8.

[9] Masselink, M., Van Roekel, E., \& Oldehinkel, A. (2018). Self-esteem in early adolescence as predictor of depressive symptoms in late adolescence and early adulthood: The mediating role of motivational and social factors. J. Youth Adolesc. (47). pp. 932 - 946.

[10] Orth, U., \& Robins, R.W. (2013). Understanding the link between low self-esteem and depression. Curr. Dir. Psychol. Sci. (22). pp. 455-460.

[11] Zeigler-Hill, V. (2011). The connections between self-esteem and psycho-pathology. J. Contemp. Psychother. (41). pp. 157-164.

[12] Shahar, G., \& Davidson, L. (2003). Depressive symptoms erode self- esteem in severe mental illness: A three-wave, cross-lagged study. J. Consult. Clin. Psychol. (71). pp. 890-900.

[13] Deng, Y., Li, X., Liu, L., \& Chui, W. H. (2020). Suicide Attempts and Perceived Social Support among Chinese Drug Users: The Mediating Role of Self-Esteem and Depression. Int. J. Environ. Res. Public Health. (18)208. https://doi.org/10.3390/ijerph18010208

[14] Lee, Hyun J., Lee, Dong K., \& Song, Wonkyong. (2019). Relationships between Social Capital, Social Capital Satisfaction, Self-Esteem, and Depression among Elderly Urban Residents: Analysis of Secondary Survey Data. Int. J. Environ. Res. Public Health. (16)1445; https://doi.org/10.3390/ijerph16081445

[15] Sowislo, J.F., \& Orth, U. (2013). Does low self-esteem predict depression and anxiety? A meta-analysis of longitudinal studies. Psychol. Bull. (139)213-240.

[16] Sakellari, E., Psychogiou, M., Georgiou, A., Papanidi, M., Vlachou, V., \& Sapountzi-Krepia, D. (2018). Exploring religiosity, self-esteem, stress, and depression among students of a cypriot university. J. Relig. Health. (57)136-145. 
[17] Cho, H.W., \& Woo, J.Y. (2013). The relational structure modeling between variables related with postpartum depression. Korean J. Counsel. Psychotherapy (25)549-573.

[18] Friedman, S.H., \& Resnick, P.J. (2009). Children of depressed parents: An integrative review. Women's Health (5)287-295.

[19] Woolhouse, H., Gartland, D., Perlen, S., Donath, S., \& Brown, S.J. (2014). Physical health after childbirth and maternal depression in the first 12 months post-partum: Results of an Australian nulliparous pregnancy cohort study. Midwifery (30)378-384

[20] Garaigordobil, M., \& Durá, A. (2006). Relaciones del autoconcepto y la autoestima con la sociabilidad, estabilidad emocional y responsabilidad en adolescentes de 14 a 17 años. Anál. Modif. Conducta (32)37-64.

[21] R Bipeta, SSRR Yerramilli, \& SV Pillutla (2020). Perceived Stigma in Remitted Psychiatric Patients and their Caregivers and its Association with Self-Esteem, Quality of Life, and Caregiver Depression. East Asian Arch Psychiatry. (101)7, https://doi.org/10.12809/eaap1943

[22] American Psychiatric Association (2013). Diagnostic and Statistical Manual of Mental Disorders, Fifth Edition (DSM-5).

[23] Masten, A. S. (2001). Ordinary magic: Resilience processes in development. American Psychologist. 56(3). pp. 227-238. doi:10.1037/0003-066X.56.3.227.

[24] Christopher, J. M. (1995). Self-esteem Research, Theory, and Practice. p. 88.

[25] Parra, A., Oliva, A., \& Sánchez-Queija, I. (2004). Evolución y determinantes de la autoestima durante los años adolescentes. Anu. Psicol. (35)331-346.

[26] Erol, R.Y., \& Orth, U. (2011). Self-esteem development from age 14 to 30 years: A longitudinal study. J. Pers. Soc. Psychol. (101)607.

[27] Peláez-Fernández, M.A., Rey, L., \& Extremera, N. (2021). A Sequential Path Model Testing: Emotional Intelligence, Resilient Coping and Self-Esteem as Predictors of Depressive Symptoms during Unemployment. Int. J. Environ. Res. Public Health.

(18)697. https://doi.org/10.3390/ijerph18020697

[28] Assari, S., \& Lankarani, M. M. (2018). Depressive Symptoms and Self-Esteem in White and Black
Older Adults in the United States. Brain Sci. (8)105. https://doi.org/10.3390/brainsci8060105

[29] Han, Jeong-Won, \& Kim, Da-Jung (2020). Longitudinal Relationship Study of Depression and Self-Esteem in Postnatal Korean Women Using Autoregressive Cross-Lagged Modeling. Int. J. Environ. Res. Public Health (17)3743; https://doi.org/10.3390/ijerph17103743

[30] Kayani, S., Kiyani, T., Wang, J., Sánchez, M. L. Z., Kayani, S., \& Qurban H. (2018). Physical Activity and Academic Performance: The Mediating Effect of Self-Esteem and Depression. Sustainability.

(10)3633 https://doi.org/10.3390/su10103633

[31] Leung, A. N. M., Law, W., Liang, Y. Y., Au, A. C. L., Li, C., \& Ng, H. K. S. (2021). What Explains the Association between Usage of Social Networking Sites (SNS) and Depression Symptoms? The Mediating Roles of Self-Esteem and Fear of Missing Out. Int. J. Environ. Res. Public Health. (18)3916. https://doi.org/10.3390/ijerph18083916

[32] Peñate, W., González-Loyola M., \& Oyanadel C. (2020). The Predictive Role of Affectivity, Self-Esteem and Social Support in Depression and Anxiety in Children and Adolescents. Int. J. Environ. Res. Public Health. (17)6984. https://doi.org/10.3390/ijerph17196984 